\title{
Composition dependence of absorption edge energy of borate glasses containing a large amount of $\mathrm{Bi}_{2} \mathrm{O}_{3}$
}

\author{
Kohei FUKUMI ${ }^{1, \dagger}$, Naoyuki KITAMURA ${ }^{1}$ and Hiromitsu KOZUKA ${ }^{2}$ \\ ${ }^{1}$ National Institute of Advanced Industrial Science and Technology, 1-8-31 Midorigaoka, Ikeda, Osaka 563-8577, Japan \\ ${ }^{2}$ Department of Chemistry and Materials Engineering, Faculty of Chemistry, Materials and Bioengineering, Kansai University, \\ 3-3-35 Yamate, Suita, Osaka, 564-8680, Japan
}

\begin{abstract}
Absorption edge energy has been studied in $\mathrm{Bi}_{2} \mathrm{O}_{3}-\mathrm{B}_{2} \mathrm{O}_{3}$, and $\left(\mathrm{Li}_{2} \mathrm{O}, \mathrm{Na}_{2} \mathrm{O}, \mathrm{K}_{2} \mathrm{O}, \mathrm{CaO}, \mathrm{BaO}, \mathrm{ZnO}, \mathrm{Ga}_{2} \mathrm{O}_{3}\right.$ and $\left.\mathrm{Nb}_{2} \mathrm{O}_{5}\right)-\mathrm{Bi}_{2} \mathrm{O}_{3}-\mathrm{B}_{2} \mathrm{O}_{3}$ glasses containing a large amount of $\mathrm{Bi}_{2} \mathrm{O}_{3}$. It was found that the absorption edge energy obeyed Duffy's theoretical basicity formula, that is, the additivity rule with glass composition. The additivity factor depended on electronegativity of each constituent atom, except bismuth. The additivity factor of $\mathrm{Bi}_{2} \mathrm{O}_{3}$ was much smaller than that expected from electronegativity. The small value of additivity factor of $\mathrm{Bi}_{2} \mathrm{O}_{3}$ was discussed on the basis of $\mathrm{Bi}-\mathrm{O}-\mathrm{Bi}$ bond formation.

(C2019 The Ceramic Society of Japan. All rights reserved.
\end{abstract}

Key-words : Bismuth borate, Glass, Absorption edge energy

[Received February 14, 2019; Accepted May 20, 2019]

\section{Introduction}

Bismuth oxide attracts attention as an alternative of lead oxide in glass industry from the view point of environmental issue, since bismuth oxide has low toxicity and the addition of bismuth oxide into glasses lowers glass transition temperature and increases refractive index. ${ }^{1-17)}$ It is known, however, that addition of a large amount of bismuth oxide colors glasses yellow or yellowish brown. The former and the latter colors are due to bismuth ions and bismuth metallic colloid, respectively. ${ }^{18)}$ Although the browning, that is, the formation of bismuth colloid, can be avoided by decreasing the melting temperature, the yellowing is the intrinsic nature of bismuth ions and is inevitable.

Bismuth containing borate glasses have been studied and have been developed for the production of lenses by a press forming method. ${ }^{15)-17)}$ As a matter of course, colorless glass is preferable for the use of lenses. Therefore, it is important to study the relationship between the color of bismuth-rich glasses and the glass composition. In a previous study, we studied the compositional dependence of short-wavelength absorption edge energy in various bismuth-rich phosphate glasses in detail. ${ }^{12)}$ In bismuth-rich borate glasses, many researches have been conducted on the absorption edge energy. ${ }^{1-4)}$ It has been reported that the absorption edge energy shifted toward lower energy with increasing $\mathrm{Bi}_{2} \mathrm{O}_{3}$ content in $\mathrm{Bi}_{2} \mathrm{O}_{3}-\mathrm{B}_{2} \mathrm{O}_{3}, \mathrm{Li}_{2} \mathrm{O}-\mathrm{Bi}_{2} \mathrm{O}_{3}-$ $\mathrm{B}_{2} \mathrm{O}_{3}$ and $\mathrm{ZnO}-\mathrm{Bi}_{2} \mathrm{O}_{3}-\mathrm{B}_{2} \mathrm{O}_{3}{ }^{1{ }^{1)-3)}}$ However, the relationship

\footnotetext{
Corresponding author: K. Fukumi; E-mail: fukumi-kohei@ aist.go.jp
}

between the absorption edge energy and the composition has not been studied in detail within the bismuth rich borate glasses. In the present study, we have studied the absorption edge energy of bismuth containing borate glasses in the bismuth-rich region and discussed the relationship between the absorption edge energy and the composition.

\section{Experimental procedures}

Glasses listed in Table 1 were prepared by a conventional melting method. Glass compositions were chosen by reference to glass forming regions in Ref. 19. Reagent grade $\mathrm{Bi}_{2} \mathrm{O}_{3}$ (Wako Chemicals, 99.9\%), $\mathrm{B}_{2} \mathrm{O}_{3}$ (Kanto Chemicals, 95.0\%), $\mathrm{CaCO}_{3}$ (Kojundo Chemicals, 99\%), $\mathrm{BaCO}_{3}$ (Kojundo Chemicals, 99.5\%), ZnO (High Purity Chemicals, 99.9\%), $\mathrm{Li}_{2} \mathrm{CO}_{3}$ (Kojundo Chemicals, 99\%), $\mathrm{Na}_{2} \mathrm{CO}_{3}$ (Kojundo Chemicals, 99\%), $\mathrm{K}_{2} \mathrm{CO}_{3}$ (Kojundo Chemicals, 99\%), $\mathrm{Ga}_{2} \mathrm{O}_{3}$ (Kisida, 99.999\%) and $\mathrm{Nb}_{2} \mathrm{O}_{5}$ (Wako Chemicals, 99.9\%) were used as raw materials. The appropriate mixture of these raw materials was melted in a $\mathrm{Pt}$ crucible for $1 \mathrm{~h}$ at temperatures from 800 to $900^{\circ} \mathrm{C}$ by an electrically heating furnace in an ambient atmosphere, except for $\mathrm{Nb}_{2} \mathrm{O}_{5}-\mathrm{Bi}_{2} \mathrm{O}_{3}-\mathrm{B}_{2} \mathrm{O}_{3}$ glasses which were melted at temperatures from 950 to $1050^{\circ} \mathrm{C}$. The melt was poured onto a carbon plate and annealed at about glass transition temperature to obtain glass with a weight of $20 \mathrm{~g}$ and a thickness of 1-3 mm. The glasses were transparent and were colorless, pale-yellow, yellow or chrome yellow. The glass was cut and polished for the measurements of optical absorption spectra, reflection spectra and refractive index. In addition, a thin $50 \mathrm{Bi}_{2} \mathrm{O}_{3} \cdot 50 \mathrm{~B}_{2} \mathrm{O}_{3}$ glass film was prepared from a glass balloon. The thickness of the thin film was estimated to be about $1.3 \mu \mathrm{m}$ from the period of 
Table 1. Nominal composition and properties of bismuth borate glasses

\begin{tabular}{|c|c|c|c|c|c|c|c|}
\hline \multicolumn{3}{|c|}{$\begin{array}{c}\text { Nominal } \\
\text { Composition } / \mathrm{mol} \%\end{array}$} & \multirow[t]{2}{*}{$n$} & \multirow[t]{2}{*}{$\begin{array}{c}d \\
\mathrm{~g} \mathrm{~cm}^{-3}\end{array}$} & \multirow[t]{2}{*}{$\begin{array}{l}\mathrm{Tg} \\
{ }^{\circ} \mathrm{C}\end{array}$} & \multirow[t]{2}{*}{$\begin{array}{c}E_{\text {edge }} \\
\text { eV }\end{array}$} & \multirow[t]{2}{*}{$\begin{array}{c}E_{\text {ref }} \\
\mathrm{eV}\end{array}$} \\
\hline $\mathrm{B}_{2} \mathrm{O}_{3}$ & $\mathrm{Bi}_{2} \mathrm{O}_{3}$ & $\mathrm{Li}_{2} \mathrm{O}$ & & & & & \\
\hline 40.0 & 60.0 & - & 2.207 & 7.449 & 356 & 2.91 & 4.05 \\
\hline 50.0 & 50.0 & - & 2.115 & 6.883 & 392 & 3.07 & 4.20 \\
\hline 60.0 & 40.0 & - & 2.014 & 6.226 & 427 & 3.21 & 4.35 \\
\hline 70.0 & 30.0 & - & 1.897 & 5.342 & 451 & 3.33 & 4.52 \\
\hline 35.0 & 55.0 & 10.0 & 2.184 & 7.220 & 330 & 2.85 & - \\
\hline 30.0 & 50.0 & 20.0 & 2.165 & 6.964 & 302 & 2.72 & 3.77 \\
\hline 25.0 & 45.0 & 30.0 & 2.135 & 6.684 & 288 & 2.71 & - \\
\hline 45.0 & 45.0 & 10.0 & 2.089 & 6.639 & 361 & 3.01 & 4.11 \\
\hline 40.0 & 40.0 & 20.0 & 2.062 & 6.344 & 335 & 2.94 & 3.97 \\
\hline 35.0 & 35.0 & 30.0 & 2.025 & 5.990 & 308 & 2.85 & - \\
\hline 55.0 & 35.0 & 10.0 & 1.982 & 5.911 & 403 & 3.15 & 4.32 \\
\hline 50.0 & 30.0 & 20.0 & 1.959 & 5.662 & 375 & 3.07 & - \\
\hline 45.0 & 25.0 & 30.0 & 1.912 & 5.189 & 344 & 2.96 & 4.22 \\
\hline 65.0 & 25.0 & 10.0 & 1.859 & 5.010 & 433 & 3.28 & 4.38 \\
\hline 60.0 & 20.0 & 20.0 & 1.829 & 4.661 & 417 & 3.21 & 4.43 \\
\hline 55.0 & 15.0 & 30.0 & 1.774 & 4.202 & 400 & 3.17 & 4.36 \\
\hline 75.0 & 15.0 & 10.0 & 1.724 & 3.939 & 453 & 3.42 & 4.56 \\
\hline 70.0 & 10.0 & 20.0 & 1.677 & 3.485 & 451 & 3.39 & 4.64 \\
\hline $\mathrm{B}_{2} \mathrm{O}_{3}$ & $\mathrm{Bi}_{2} \mathrm{O}_{3}$ & $\mathrm{ZnO}$ & & & & & \\
\hline 35.0 & 55.0 & 10.0 & 2.204 & 7.439 & 354 & 2.90 & 3.80 \\
\hline 30.0 & 50.0 & 20.0 & 2.197 & 7.363 & 349 & 2.95 & 3.99 \\
\hline 25.0 & 45.0 & 30.0 & 2.190 & 7.334 & 348 & 2.88 & 3.97 \\
\hline 45.0 & 45.0 & 10.0 & 2.108 & 6.863 & 393 & 3.04 & 4.11 \\
\hline 40.0 & 40.0 & 20.0 & 2.096 & 6.778 & 390 & 3.06 & 4.15 \\
\hline 35.0 & 35.0 & 30.0 & 2.083 & 6.702 & 387 & 3.05 & 4.11 \\
\hline 55.0 & 35.0 & 10.0 & 2.004 & 6.153 & 433 & 3.19 & 4.30 \\
\hline 50.0 & 30.0 & 20.0 & 1.986 & 6.049 & 430 & 3.19 & 4.20 \\
\hline 45.0 & 25.0 & 30.0 & 1.957 & 5.893 & 428 & 3.19 & 4.30 \\
\hline 65.0 & 25.0 & 10.0 & 1.882 & 5.238 & 461 & 3.32 & 4.52 \\
\hline 60.0 & 20.0 & 20.0 & $1.856^{*}$ & 5.139 & 463 & 3.31 & 4.51 \\
\hline 55.0 & 15.0 & 30.0 & 1.824 & 4.828 & 486 & 3.31 & 4.43 \\
\hline $\mathrm{B}_{2} \mathrm{O}_{3}$ & $\mathrm{Bi}_{2} \mathrm{O}_{3}$ & $\mathrm{Ga}_{2} \mathrm{O}_{3}$ & & & & & \\
\hline 25.0 & 65.0 & 10.0 & 2.255 & 7.739 & 348 & 2.80 & 3.80 \\
\hline 35.0 & 55.0 & 10.0 & 2.171 & 7.267 & 374 & 2.97 & 4.17 \\
\hline 45.0 & 45.0 & 10.0 & 2.080 & 6.693 & 409 & 3.11 & 4.23 \\
\hline 55.0 & 35.0 & 10.0 & 1.979 & 6.011 & 442 & 3.23 & 4.35 \\
\hline 65.0 & 25.0 & 10.0 & 1.865 & 5.138 & 472 & 3.36 & 4.56 \\
\hline $\mathrm{B}_{2} \mathrm{O}_{3}$ & $\mathrm{Bi}_{2} \mathrm{O}_{3}$ & $\mathrm{Nb}_{2} \mathrm{O}_{5}$ & & & & & \\
\hline 57.5 & 37.5 & 5.0 & 2.043 & 6.116 & 447 & 3.16 & 4.35 \\
\hline 55.0 & 35.0 & 10.0 & $2.075^{*}$ & 5.994 & 456 & 3.09 & - \\
\hline 67.5 & 27.5 & 5.0 & 1.925 & 5.217 & 461 & 3.26 & 4.46 \\
\hline $\mathrm{B}_{2} \mathrm{O}_{3}$ & $\mathrm{Bi}_{2} \mathrm{O}_{3}$ & $\mathrm{Na}_{2} \mathrm{O}$ & & & & & \\
\hline 55.0 & 35.0 & 10.0 & 1.951 & 5.881 & 381 & 3.09 & - \\
\hline $\mathrm{B}_{2} \mathrm{O}_{3}$ & $\mathrm{Bi}_{2} \mathrm{O}_{3}$ & $\mathrm{~K}_{2} \mathrm{O}$ & & & & & \\
\hline 65.8 & 29.0 & 5.2 & 1.862 & 5.155 & 425 & 3.23 & - \\
\hline $\mathrm{B}_{2} \mathrm{O}_{3}$ & $\mathrm{Bi}_{2} \mathrm{O}_{3}$ & $\mathrm{CaO}$ & & & & & \\
\hline 55.0 & 35.0 & 10.0 & 1.995 & 6.009 & 436 & 3.14 & 4.26 \\
\hline $\mathrm{B}_{2} \mathrm{O}_{3}$ & $\mathrm{Bi}_{2} \mathrm{O}_{3}$ & $\mathrm{BaO}$ & & & & & \\
\hline 55.0 & 35.0 & 10.0 & 1.994 & 6.150 & 417 & 3.10 & - \\
\hline
\end{tabular}

$n$ : refractive index, $d$ : density, $T g$ : glass transition temperature, $E_{\text {edge }}$ : absorption edge energy, $E_{\text {ref: }}$ peak energy of reflection spectra. The errors in $n$ and $d$ were within 0.002 except the data marked with *: The error marked with * was within 0.004

interference pattern observed in the transmission spectrum and the refractive index.

Near infrared-visible-ultra violet absorption spectra of all the glasses were measured with a conventional spec- trophotometer (Hitachi U-4000) in the regions from 190 to $800 \mathrm{~nm}$. Ultraviolet reflection spectra of some glasses were measured with the same spectrometer equipped with the reflection measurement attachment in the region from 200 to $600 \mathrm{~nm}$. The incident and take-off angles were kept at an angle of $10^{\circ}$ off normal incidence in the reflection measurement. Refractive index at $632.8 \mathrm{~nm}$ was measured by a prism coupling method (Metricon, Model 2010 Prism Coupler). The measurement error was almost always within 0.002. Glass transition temperature was measured with a differential thermal analyzer (Rigaku, Thermo plus TG8120) or a differential scanning calorimeter (SII, EXSTAR 600 DSC 5300). Density was measured by the Archimedes' method. The measurement error was almost always less than $0.002 \mathrm{~g} \mathrm{~cm}^{-3}$.

The absorption coefficient, $\alpha$, of $50 \mathrm{Bi}_{2} \mathrm{O}_{3} \cdot 50 \mathrm{~B}_{2} \mathrm{O}_{3}$ glass was calculated from absorbance (ln $T$; $T$ : total transmittance) and sample thickness, following the subtraction of the effect of reflection at sample surfaces. The effect of reflection was estimated from the reflection spectrum or the difference in transmittance of samples with different thickness.

Molar absorption coefficient of $\mathrm{Bi}_{2} \mathrm{O}_{3}, \kappa$, of all the glasses was calculated from absorbance by subtracting the effect of reflection which was assumed to be the absorbance at $800 \mathrm{~nm}$, and by being divided by the sample thickness and the molar concentration of $\mathrm{Bi}_{2} \mathrm{O}_{3}$. The absorption edge energy, $E_{\text {edge, }}$, was defined as the energy at which $\kappa$ was unity. Specifically, $E_{\text {edge }}$ was obtained by fitting the function $\exp \left[B\left(E-E_{\text {edge }}\right)\right],{ }^{20)}$ where $B$ is the slope of exponential function and $E$ is the photon energy, to a $\kappa$ vs. $E$ curve in the region from 2 to $3 \mathrm{Bi}_{2} \mathrm{O}_{3}$ $\mathrm{mol}^{-1} \mathrm{dm}^{3} \mathrm{~cm}^{-1}$. The peak energy in the reflection spectra was obtained after smoothing the spectra. The measurement error of the peak energy was about $0.1 \mathrm{eV}$, since the reflection bands were very broad.

\section{Results}

Density, refractive index and glass transition temperature are summarized in Table 1. Figure 1 shows transmission spectra and a reflection spectrum of $50 \mathrm{Bi}_{2} \mathrm{O}_{3} \cdot 50 \mathrm{~B}_{2} \mathrm{O}_{3}$ glass, along with a transmission spectrum of $\mathrm{B}_{2} \mathrm{O}_{3}$ glass. No absorption peak was observed up to $3.8 \mathrm{eV}$ in the transmission spectra of $50 \mathrm{Bi}_{2} \mathrm{O}_{3} \cdot 50 \mathrm{~B}_{2} \mathrm{O}_{3}$ glass. An interference pattern was observed in the sample with a thickness of 1.3 $\mu \mathrm{m}$. A peak was observed at about $4.0 \mathrm{eV}$ in the reflection spectrum of $50 \mathrm{Bi}_{2} \mathrm{O}_{3} \cdot 50 \mathrm{~B}_{2} \mathrm{O}_{3}$ glass. No absorption bands were observed at energies lower than $5.5 \mathrm{eV}$ in the spectrum of $\mathrm{B}_{2} \mathrm{O}_{3}$ glass, although the weak interference with a long period was observed.

Figure 2 shows the molar absorption coefficient and reflection spectra of some representative glasses. The absorption edge shifted toward lower energy with the substitution of $\mathrm{Bi}_{2} \mathrm{O}_{3}$ for $\mathrm{B}_{2} \mathrm{O}_{3}$. The absorption edge energies, $E_{\text {edge }}$, are summarized in Table 1 . The value of $B$ ranged from 8 to 12 . A peak was observed in the region from 3.7 to $4.6 \mathrm{eV}$ in the reflection spectra. The peak energy shifted toward lower energy with the substitution of $\mathrm{Bi}_{2} \mathrm{O}_{3}$ for 


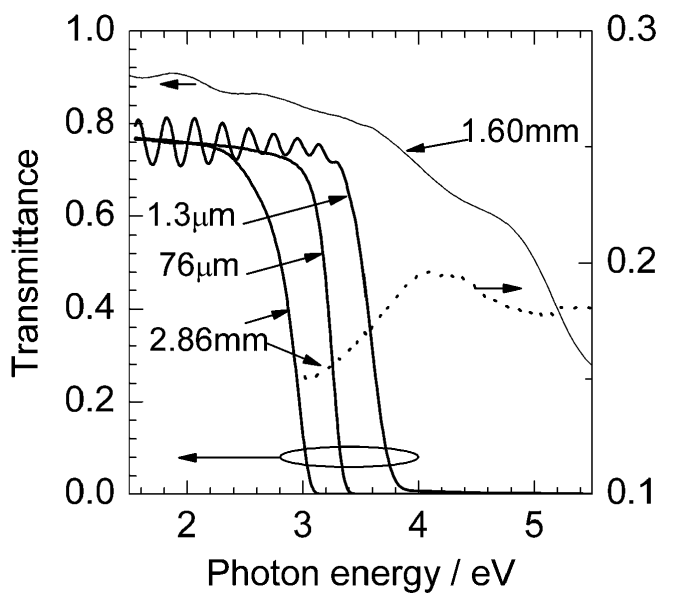

Fig. 1. Transmittance and reflectance of $50 \mathrm{Bi}_{2} \mathrm{O}_{3} \cdot 50 \mathrm{~B}_{2} \mathrm{O}_{3}$ glass along with transmittance of $\mathrm{B}_{2} \mathrm{O}_{3}$ glass. Thick solid and dotted lines represent transmittance and reflectance of $50 \mathrm{Bi}_{2} \mathrm{O}_{3} \cdot 50 \mathrm{~B}_{2} \mathrm{O}_{3}$ glass, respectively. A thin line represents transmittance of $\mathrm{B}_{2} \mathrm{O}_{3}$ glass. Numerical values show thickness of samples.

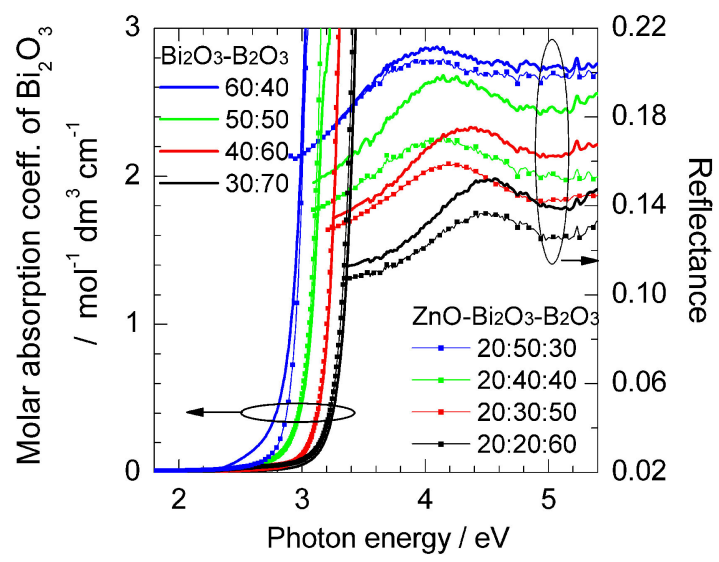

Fig. 2. Molar absorption coefficient of $\mathrm{Bi}_{2} \mathrm{O}_{3}$ and reflectance of $\mathrm{Bi}_{2} \mathrm{O}_{3}-\mathrm{B}_{2} \mathrm{O}_{3}$ and $\mathrm{ZnO}-\mathrm{Bi}_{2} \mathrm{O}_{3}-\mathrm{B}_{2} \mathrm{O}_{3}$ glasses.

$\mathrm{B}_{2} \mathrm{O}_{3}$. The reflection peak energies observed in the reflection spectra, $E_{\text {ref, }}$ are shown in Table 1.

\section{Discussion}

\subsection{Relationship between absorption edge energy and reflection peak energy}

The reflection spectrum of $50 \mathrm{Bi}_{2} \mathrm{O}_{3} \cdot 50 \mathrm{~B}_{2} \mathrm{O}_{3}$ glass showed a peak at about $4.0 \mathrm{eV}$, as depicted in Fig. 1. No absorption bands and reflection peaks were observed below $3.8 \mathrm{eV}$ in the transmission and reflection spectra of $50 \mathrm{Bi}_{2} \mathrm{O}_{3} \cdot 50 \mathrm{~B}_{2} \mathrm{O}_{3}$ glass. These findings indicate that the absorption around absorption edge $(3.01 \mathrm{eV})$ was the tail part of the absorption band observed in the reflection spectrum. The transmission spectrum of $\mathrm{B}_{2} \mathrm{O}_{3}$ glass showed no absorption bands at energies lower than $5.4 \mathrm{eV}$, although the interference pattern, probably due to the formation of very thin corrosion layers, and the gradual decrease in transmittance toward higher energies, probably due to the scattering of light by the corrosion layers, were observed. In addition, it has been reported that no remarkable

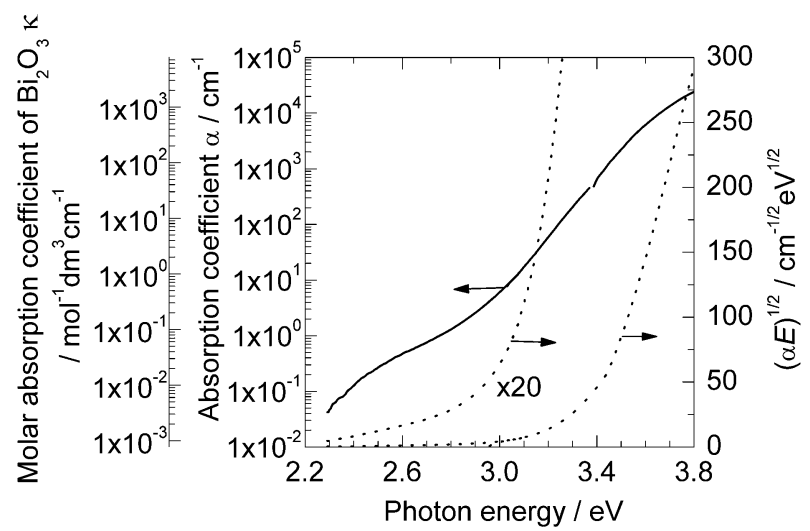

Fig. 3. Molar absorption coefficient of $\mathrm{Bi}_{2} \mathrm{O}_{3}$, absorption coefficient $\alpha$ and $(\alpha \mathrm{E})^{1 / 2}$ of $50 \mathrm{Bi}_{2} \mathrm{O}_{3} \cdot 50 \mathrm{~B}_{2} \mathrm{O}_{3}$ glass.

absorption is observed in the region below $5.4 \mathrm{eV}$ in alkali borate glasses. ${ }^{21)}$ The absence of absorption bands below $5.4 \mathrm{eV}$ indicates that the reflection peak at about $4.0 \mathrm{eV}$ in $50 \mathrm{Bi}_{2} \mathrm{O}_{3} \cdot 50 \mathrm{~B}_{2} \mathrm{O}_{3}$ glass was due to $\mathrm{Bi}$ atoms. Since it is known that an absorption band due to $\mathrm{Bi}^{3+}$ ions is present in the region from 4.5 to $5.5 \mathrm{eV}$ in $\mathrm{Bi}_{2} \mathrm{O}_{3}$-doped glasses, ${ }^{22)}$ it was inferred that the reflection peak in the region from 3.7 to $4.6 \mathrm{eV}$ originated from the absorption due to $\mathrm{Bi}^{3+}$ ions in the present glasses. That is, the absorption edge was due to the absorption by $\mathrm{Bi}^{3+}$ ions in the present glasses.

Figure 3 displays $(\alpha E)^{1 / 2}$ and $\alpha$ of $50 \mathrm{Bi}_{2} \mathrm{O}_{3} \cdot 50 \mathrm{~B}_{2} \mathrm{O}_{3}$ glass. $\alpha$ increased exponentially with an increase in energy in the energy region from 2.9 to $3.6 \mathrm{eV}$ ( $\alpha$ from $2 \times 10^{0}$ to $5 \times 10^{3} \mathrm{~cm}^{-1}, \kappa$ from 0.16 to $390 \mathrm{~mol}^{-1} \mathrm{dm}^{3} \mathrm{~cm}^{-1}$ ). The exponential dependence of edge profile is characteristic of disordered materials. ${ }^{20)}$ On the other hand, $(\alpha E)^{1 / 2}$ did not increase linearly with an increase in energy in the energy region lower than $3.6 \mathrm{eV}$, showing that the absorption edge profile did not obey the so-called Tauc's relation: $^{20)}(\alpha E)^{1 / 2} \propto\left(E-E_{\text {edge }}\right)$, in this region.

Since the absorption edge was due to the absorption by $\mathrm{Bi}^{3+}$ ions in the present glasses, it is natural that the absorption coefficient around absorption edge should be proportional to molar concentration of $\mathrm{Bi}^{3+}$ ions, $c$. In fact, the value of $B$ was independent of $c$. Therefore, the absorption edge energy was obtained from the molar absorption coefficient of $\mathrm{Bi}_{2} \mathrm{O}_{3}, \kappa$.

Figure 4 shows the relationship between the absorption edge energy and the position of reflection peak. The absorption edge energy increased with an increase in energy of reflection peak with a proportional constant near unity (1.15). Therefore, it was inferred that the shift of absorption edge toward lower energy was due to the shift of the absorption band which caused the reflection peak in the region from 3.7 to $4.6 \mathrm{eV}$.

\subsection{Relationship between absorption edge energy and electronegativity}

Ingram and Duffy have defined the optical basicity expressed by Eq. (1) as a measure of average electron donation power of oxide ions in glass, ${ }^{22)}$ 


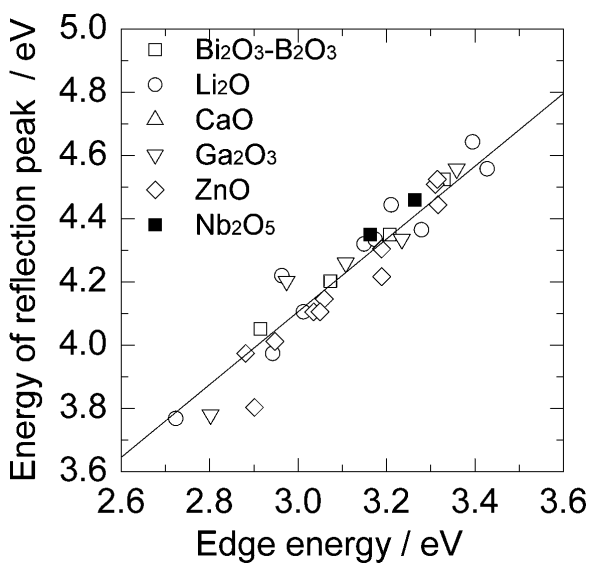

Fig. 4. Relationship between absorption edge energy and reflection peak energy.

$$
\Lambda_{\mathrm{opt}}=\frac{6.94-E_{\mathrm{p}}}{3.57}=\frac{E_{\mathrm{p}}-6.94}{-3.57}
$$

where $\Lambda_{\mathrm{opt}}$ and $E_{\mathrm{p}}$ represent the optical basicity of glass and the absorption peak energy of the $\mathrm{Bi}^{3+}$ ions obtained experimentally, respectively. This equation implies that the absorption peak energy shifts linearly toward lower energy with an increase in basicity of Bi-doped glasses, that is, with an increase in electron donation power of oxide ions and the decrease in ionicity of $\mathrm{Bi}-\mathrm{O}$ bonds. In addition, they have shown that $\Lambda_{\text {opt }}$ is related with the basicity assigned to individual oxides by Eq. (2), ${ }^{22)}$

$$
\begin{aligned}
& \Lambda_{\mathrm{opt}}=\Lambda_{\mathrm{th}}=\sum_{i} \Lambda_{i} X_{i} \\
& \sum_{i} X_{i}=1
\end{aligned}
$$

where $\Lambda_{\mathrm{th}}, \Lambda_{i}$ and $X_{i}$ are the theoretical basicity of glass, the basicity assigned to individual oxides $i$ and the fraction of the amount of oxygen atoms in each constituent oxide $i$ to the total amount of oxygen atoms in glass, respectively. Combining Eqs. (1) and (2) and letting $E_{\text {edge }}=E_{\mathrm{p}}-\Delta$ gives Eq. (3),

$$
E_{\text {edge }}=\sum_{i}\left(6.94-\Delta-3.57 \Lambda_{i}\right) X_{i}
$$

where $\Delta$ represents the difference between $E_{\text {edge }}$ and $E_{\mathrm{p}} . \Delta$ is constant, since the absorption edge energy increases with an increase in reflection peak energy with a proportional constant of almost unity. It was anticipated from Eq. (3) that $E_{\text {edge }}$ was expressed by the additivity rule with respect to $X_{i}$. Figure 5 shows the relationship between $E_{\text {edge }}$ obtained experimentally and that calculated from additivity rule using factors obtained by linear least-squares regression. It was found that $E_{\text {edge }}$ obeyed the additivity rule with respect to $X_{i}$, with root mean square error of $0.02 \mathrm{eV}$ and a maximum error of $0.05 \mathrm{eV}$. The additivity factors for

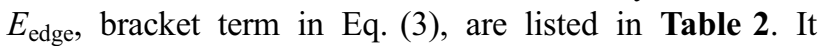
should be noted that $E_{\text {edge }}$ obeyed the additivity rule with respect to, not only $X_{i}$ but also the molar fraction of each oxide. Nevertheless, the additivity rule with respect to $X_{i}$ was adopted in this discussion, since the additivity factor is related to electronegativity, as mentioned below.

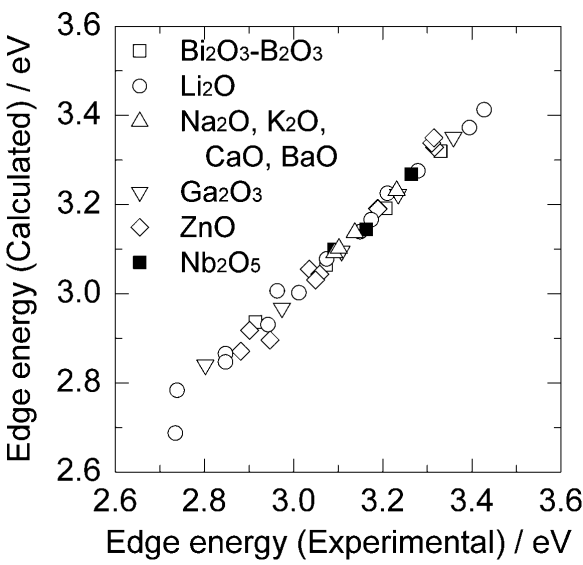

Fig. 5. Comparison of absorption edge energy obtained

\begin{tabular}{|c|c|c|c|c|c|c|c|}
\hline & $\chi_{i}$ & $S_{k}$ & & $\begin{array}{c}p_{i} \\
/ 10^{-3} \mathrm{~nm}^{3}\end{array}$ & & $\begin{array}{l}\Lambda_{i} \\
\text { from } \chi_{i} \\
{[\text { Eq. (4)] }}\end{array}$ & $\begin{array}{c}\text { Additivity factors } \\
\text { for absorption } \\
\text { edge energy/eV }\end{array}$ \\
\hline B & 2.04 & 2.275 & $\mathrm{~B}^{3+}$ & 0.0030 & $\mathrm{~B}_{2} \mathrm{O}_{3}$ & 0.42 & $3.71 \pm 0.01$ \\
\hline $\mathrm{Bi}$ & 2.02 & 2.342 & $\mathrm{Bi}^{3+}$ & 1.507 & $\mathrm{Bi}_{2} \mathrm{O}_{3}$ & 0.42 & $2.42 \pm 0.02$ \\
\hline $\mathrm{Ga}$ & 1.81 & 2.419 & $\mathrm{Ga}^{3+}$ & 0.20 & $\mathrm{Ga}_{2} \mathrm{O}_{3}$ & 0.48 & $3.38 \pm 0.12$ \\
\hline $\mathrm{Nb}$ & 1.6 & 1.42 & $\mathrm{Nb}^{5+}$ & 0.26 & $\mathrm{Nb}_{2} \mathrm{O}_{5}$ & 0.55 & $2.51 \pm 0.13$ \\
\hline $\mathrm{Li}$ & 0.98 & 0.886 & $\mathrm{Li}^{+}$ & 0.029 & $\mathrm{Li}_{2} \mathrm{O}$ & 1.03 & $1.27 \pm 0.10$ \\
\hline $\mathrm{Na}$ & 0.93 & 0.835 & $\mathrm{Na}^{+}$ & 0.181 & $\mathrm{Na}_{2} \mathrm{O}$ & 1.10 & $-0.04 \pm 0.67$ \\
\hline $\mathrm{K}$ & 0.82 & 0.445 & $\mathrm{~K}^{+}$ & 0.841 & $\mathrm{~K}_{2} \mathrm{O}$ & 1.32 & $-1.29 \pm 1.32$ \\
\hline $\mathrm{Ca}$ & 1.00 & 0.946 & $\mathrm{Ca}^{2+}$ & 0.472 & $\mathrm{CaO}$ & 1.00 & $1.24 \pm 0.67$ \\
\hline $\mathrm{Ba}$ & 0.89 & 0.683 & $\mathrm{Ba}^{2+}$ & 1.56 & $\mathrm{BaO}$ & 1.17 & $0.24 \pm 0.67$ \\
\hline $\mathrm{Zn}$ & 1.65 & 2.223 & $\mathrm{Zn}^{2+}$ & 0.29 & $\mathrm{ZnO}$ & 0.54 & $2.79 \pm 0.10$ \\
\hline $\mathrm{O}$ & & 3.654 & & & & & \\
\hline
\end{tabular}
experimentally and that calculated from additivity factors.

Table 2. Electronegativity, basicity, electronic polarizability of free ions and additivity factors for absorption edge energy

$\chi_{i}$ : Pauling's electronegativity, ${ }^{23)} S_{k}$ : Sanderson's electronegativity, ${ }^{30}$ ) $\Lambda_{i}$ : basicity of each oxide, $p_{i}$ : electronic polarizability of free ions. ${ }^{33), 34)}$

Duffy et al. have also proposed that $\Lambda_{i}$ can be calculated from electronegativity by Eq. (4), ${ }^{22)}$

$$
\Lambda_{i}=\frac{3}{4\left(\chi_{i}-0.25\right)}
$$

where $\chi_{i}$ is the electronegativity of cationic atom in each oxide $i$ in Pauling's scale. Figure 6 shows the relationship between the additivity factor and $\Lambda_{i}$ calculated from electronegativity ${ }^{23)}$ by Eq. (4). The additivity factor decreased linearly with $\Lambda_{i}$ with a slope of -4.68 , an intercept of 5.52 and a correlation coefficient of -0.97 , except $\mathrm{Bi}_{2} \mathrm{O}_{3}$. The ratio of the slope to the coefficient of $\Lambda_{i}$ in Eq. (4) was 1.3 $(-4.68 /-3.57)$ and was near unity, showing that $E_{\text {edge }}$ depended on $\Lambda_{i}$. That is, $E_{\text {edge }}$ was affected by the electron donation power of oxide ions which was governed by the electronegativity of cationic atoms, as expected in the concept of optical basicity. The factor for $X_{\mathrm{Bi}_{2} \mathrm{O}_{3}}$ was, however, much lower than that expected from electronegativity. This discordance indicates that the factor for $X_{\mathrm{Bi}_{2} \mathrm{O}_{3}}$ obtained experimentally includes the effect other than the electron donation power of oxide ions, which depends on $X_{\mathrm{Bi}_{2} \mathrm{O}_{3}}$. Therefore, it is expected that $E_{\text {edge }}$ is expressed by the combination of $\Lambda_{\text {th }}$ calculated from 


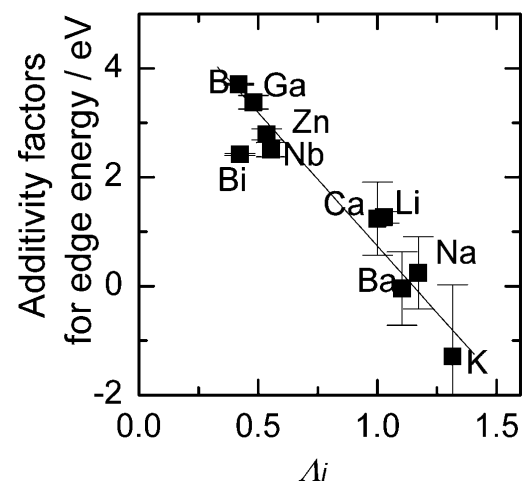

Fig. 6. Relationship between additivity factor and $\Lambda_{i}$ calculated from Pauling's electronegativity. A straight line was obtained by linear least regression without $\mathrm{Bi}$ data.

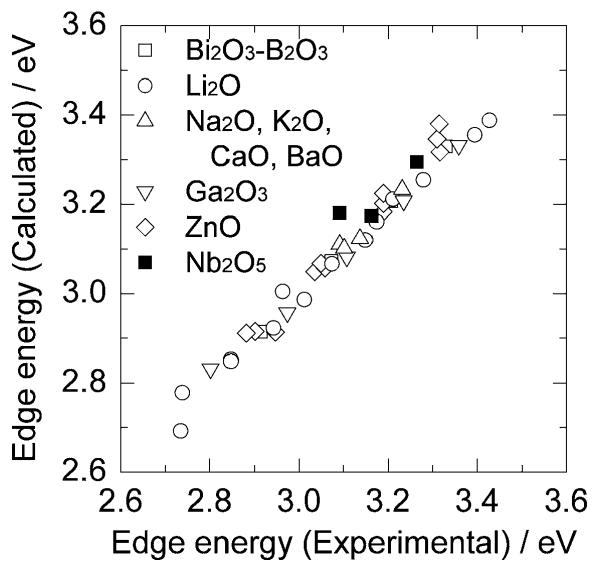

Fig. 7. Comparison of absorption edge energy obtained experimentally and that calculated from electronegativity derived basicity and $\mathrm{X}_{\mathrm{Bi}_{2} \mathrm{O}_{3}}$.

Eq. (2) and another term which is proportional to $X_{\mathrm{Bi}_{2} \mathrm{O}_{3}}$. It was found from linear least-squares regression that $E_{\text {edge }}$ was expressed by Eq. (5).

$$
E_{\text {edge }}=5.16-3.57 \sum_{i} \Lambda_{i} X_{i}-1.24 X_{\mathrm{Bi}_{2} \mathrm{O}_{3}}
$$

Figure 7 plots the $E_{\text {edge }}$ calculated from Eq. (5) against that obtained experimentally. The root mean square error and the maximum error was 0.03 and $0.09 \mathrm{eV}$, respectively. The coefficient of $\Sigma \Lambda_{i} X_{i}$ in Eq. (5) agreed with that of $\Lambda_{\mathrm{i}}$ in Eq. (3). The coincidence of the coefficients supports the validity of Eq. (5).

Since $\Sigma \Lambda_{i} X_{i}$ and $X_{\mathrm{Bi}_{2} \mathrm{O}_{3}}$ varied from 0.42 to 0.50 and from 0.12 to 0.65 , respectively, the changes in energy due to the changes in $\Sigma \Lambda_{i} X_{i}$ and $X_{\mathrm{Bi}_{2} \mathrm{O}_{3}}$ were 0.28 and $0.66 \mathrm{eV}$, respectively, in the present glasses. Therefore, it is inferred that the change in $X_{\mathrm{Bi}_{2} \mathrm{O}_{3}}$ has more effect on $E_{\text {edge }}$ than basicity in the present glasses.

In a previous study, it was reported that $\mathrm{Bi}$ atoms were located around a $\mathrm{Bi}$ atom at a distance about $0.37 \mathrm{~nm}$ through the formation of $\mathrm{Bi}-\mathrm{O}-\mathrm{Bi}$ linkages and that their number was proportional to the atomic ratio of $\mathrm{Bi}$ atoms to oxygen atoms, that is, the two-thirds of $X_{\mathrm{Bi}_{2} \mathrm{O}_{3}}$, in $\mathrm{Bi}_{2} \mathrm{O}_{3}-$ $\mathrm{B}_{2} \mathrm{O}_{3}$ and $\mathrm{Li}_{2} \mathrm{O}-\mathrm{Bi}_{2} \mathrm{O}_{3}-\mathrm{B}_{2} \mathrm{O}_{3}$ glasses. ${ }^{24)}$ On the other hand,

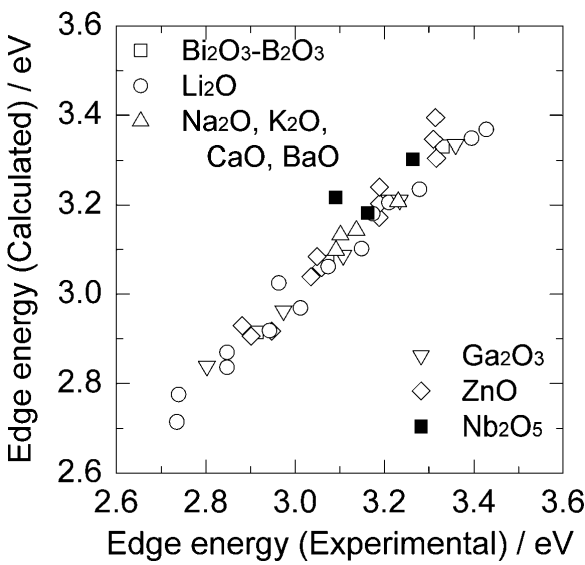

Fig. 8. Comparison of absorption edge energy obtained experimentally and that calculated from $\delta_{\mathrm{O}}$ and $X_{\mathrm{Bi}_{2} \mathrm{O}_{3}}$.

it has been shown that the nearest neighboring $\mathrm{Bi}$ atoms are located at $0.366 \mathrm{~nm}$ around a $\mathrm{Bi}$ atom in $\mathrm{BaBi}_{3}$ crystal, ${ }^{25)}$ indicating that the interaction between $\mathrm{Bi}$ atoms takes place at this distance. In addition, it has been shown from theoretical calculation that the interaction occurs at a distance of $0.390 \mathrm{~nm}$ between inter-molecular $\mathrm{Bi}$ atoms in $\mathrm{BiMe}_{3}$ molecular crystal ${ }^{26)}$ and at a distance of $0.368 \mathrm{~nm}$ between $\mathrm{Bi}-\mathrm{Bi}$ atoms in $\alpha-\mathrm{Bi}_{2} \mathrm{O}_{3}$ crystal. ${ }^{27)}$ The similarity in $\mathrm{Bi}-\mathrm{Bi}$ distance between these crystals and the present glasses is indicative of the presence of interaction between $\mathrm{Bi}$ atoms in the present glasses. Therefore, it was deduced that the bonding and antibonding interaction between $\mathrm{Bi}$ atoms took place, leading to a decrease in $E_{\text {edge }}$ in the present glasses with increasing $\mathrm{Bi}_{2} \mathrm{O}_{3}$ content. ${ }^{28)}$

Another measure of electron donation power of oxide ions is the partial charge of oxygen ions based on the electronegativity equalization principle proposed by Sanderson. ${ }^{29), 30)}$ According to Sanderson, the partial charge of an oxide ion, $\delta_{\mathrm{O}}$, is calculated from the difference between the Sanderson's electronegativity of oxygen atom, $S_{\mathrm{O}}$, and the average electronegativity, $S_{\mathrm{av}}$, [Eq. (6)].

$$
\begin{aligned}
S_{\mathrm{av}} & =\Pi_{k} S_{k}^{x_{k}} \\
\delta_{\mathrm{O}} & =\frac{S_{\mathrm{O}}-S_{\mathrm{av}}}{1.57\left(S_{\mathrm{O}}\right)^{\frac{1}{2}}}
\end{aligned}
$$

where $x_{k}$ and $S_{k}$ represents the atomic fraction of each constituent atom $k$ and its electronegativity proposed by Sanderson, respectively. Although no correlation was observed between $\delta_{\mathrm{O}}$ and $E_{\text {edge }}$ (correlation coefficient; 0.24 ), $E_{\text {edge }}$ was expressed by the combination of $\delta_{\mathrm{O}}$ and $X_{\mathrm{Bi}_{2} \mathrm{O}_{3}}$, as shown in Fig. 8. In more detail, $E_{\text {edge }}$ was expressed by Eq. (7), according to linear least-squares regression,

$$
E_{\text {edge }}=3.97-1.57 \delta_{\mathrm{O}}-1.26 X_{\mathrm{Bi}_{2} \mathrm{O}_{3}}
$$

The root mean square error and the maximum error was 0.04 and $0.13 \mathrm{eV}$, respectively. The factor of $X_{\mathrm{Bi}_{2} \mathrm{O}_{3}}$ in Eq. (7) was very similar to that in Eq. (5), although $\delta_{\mathrm{O}}$ and $\Sigma \Lambda_{i} X_{i}$ was somewhat scattered as shown in Fig. 9. This coincidence is due to the significant contribution of $X_{\mathrm{Bi}_{2} \mathrm{O}_{3}}$ on $E_{\text {edge. }}$. 


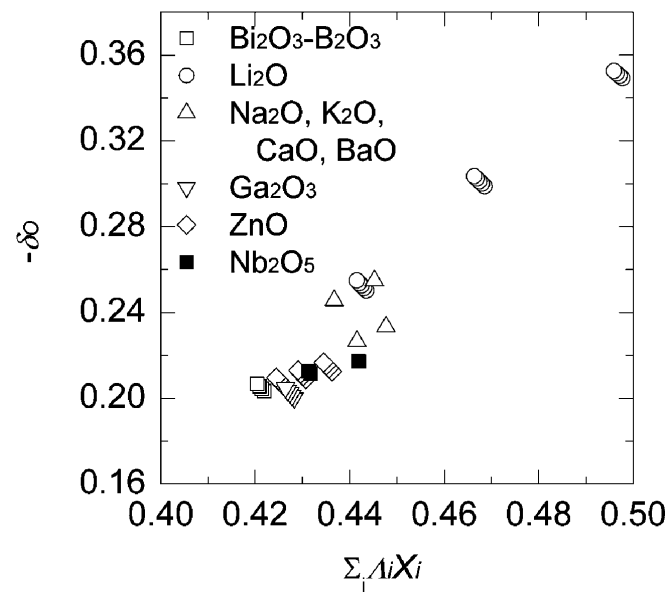

Fig. 9. Relationship between $\Sigma_{i} \Lambda_{i} X_{i}$ derived from Pauling's electronegativity and $\delta_{\mathrm{O}}$ derived from Sanderson's electronegativity.

\subsection{Relationship between absorption edge energy and refractive index}

Duffy has proposed the basicity is related with the electronic polarizability of oxide ions which is derived from the molar refraction and the electronic polarizability of free cations, assuming that the polarizability of cations in solids is similar to that of free cations. ${ }^{31), 32)}$ The basicity in glass is obtained from the refractive index by Eqs. (8a)-(8c),

$$
\begin{aligned}
& R_{\mathrm{m}}=\frac{\left(n^{2}-1\right) M}{\left(n^{2}+2\right) d} \\
& p\left(\mathrm{O}^{2-}\right)=\left(3.97 \times 10^{-4} R_{\mathrm{m}}-\sum_{j} s_{j} p_{j}\right) / t \\
& \Lambda_{n}=\frac{\left[3133 p\left(\mathrm{O}^{2-}\right)-2.868\right]^{\frac{1}{2}}}{1.567}-0.362
\end{aligned}
$$

where, $R_{\mathrm{m}}, n, M, d, p\left(\mathrm{O}^{2-}\right), p_{j}, s_{j}, t$ and $\Lambda_{n}$ represent the molar refraction, the refractive index, the molecular weight, the density, the polarizability of oxide ion, the polarizability of cation $j$, the number of each cation $j$ in the formula unit, the total number of oxide ions in the formula unit and the basicity obtained from refractive index, respectively. The polarizability of cations was obtained from Refs. 33),34). Figure 10 shows the relationship between $E_{\text {edge }}$ and $\Lambda_{n}$. Since although the data points for $\mathrm{Li}_{2} \mathrm{O}-$ $\mathrm{Bi}_{2} \mathrm{O}_{3}-\mathrm{B}_{2} \mathrm{O}_{3}$ glasses were somewhat scattered, the linear relationship was observed between $E_{\text {edge }}$ and $\Lambda_{n}$, it was possible to predict $E_{\text {edge }}$ from $\Lambda_{n}$ with a root mean square error of $0.08 \mathrm{eV}$ and a maximum error of $0.18 \mathrm{eV}$, This linear relationship was, however, caused by the linear relationship between $\Lambda_{n}$ and $X_{\mathrm{Bi}_{2} \mathrm{O}_{3}}$ (Fig. 11) and the significant contribution of $X_{\mathrm{Bi}_{2} \mathrm{O}_{3}}$ to $E_{\text {edge. }}$ Therefore, the combination of $\Lambda_{n}$ and $X_{\mathrm{Bi}_{2} \mathrm{O}_{3}}$ reduced neither the root mean square error nor the maximum error. In order to reduce the errors, it is necessary to introduce the parameters other than $X_{\mathrm{Bi}_{2} \mathrm{O}_{3}}$, in case that $\Lambda_{n}$ is adopted as ionicity to express the absorption edge energy in the present glasses.

The relationship between ionicity and refractive index has been studied in crystalline compounds by some researchers. Since Duffy has shown that $\left(n^{2}+2\right)^{2}$ is

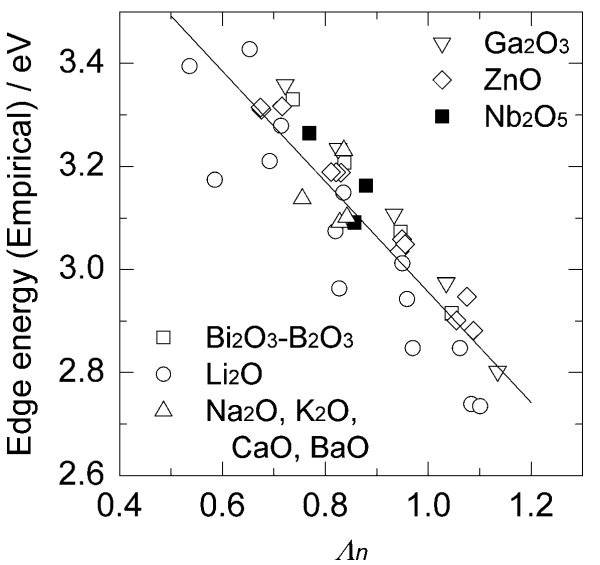

Fig. 10. Relationship between absorption edge energy obtained experimentally and $\Lambda_{n}$ obtained from refractive index. A straight line was obtained by linear least regression.

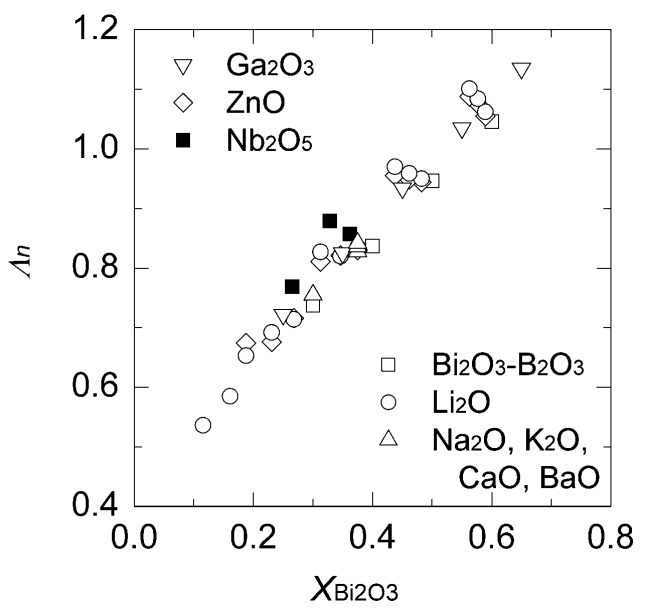

Fig. 11. Relationship between $\Lambda_{n}$ and $X_{\mathrm{Bi}_{2} \mathrm{O}_{3}}$.

inversely proportional to band gap energy, $E_{\mathrm{g}},{ }^{35)}$ it is clear that $\Lambda_{n}$ is related to $E_{\mathrm{g}}$. On the other hand, Phillips and Van Vechten $^{36)}$ and Levine ${ }^{37)}$ have shown that the susceptibility is inversely proportional to $E_{\mathrm{g}}{ }^{2}$ which is the sum of ionic and covalent contributions. Moreover, Wemple and DiDomenico have shown that $n^{2}-1$ of crystals is proportional to the dispersion energy, $E_{\mathrm{d}}$, and inversely proportional to the average single oscillator gap energy, $E_{0} \cdot{ }^{38)} E_{\mathrm{d}}$ is proportional to the product of bond character, coordination number of cations and the number of valence electrons, and the $E_{0}$ is proportional to $E_{\mathrm{g}}$. In this way, the relationship between refractive index and ionicity is very complicated. Therefore, further discussion on the relationship between $E_{\text {edge }}$ and refractive index from the view point of ionicity is beyond the scope of the present study.

\section{Conclusions}

Absorption edge energy has been measured in the borate glasses containing a large amount of $\mathrm{Bi}_{2} \mathrm{O}_{3}$. It was found that the absorption edge energy obeyed the additivity rule with respect to glass composition. The values of additivity factor depended on electronegativity of each constituent atom, except bismuth. It was deduced that the absorption 
edge energy depended on the formation of $\mathrm{Bi}-\mathrm{O}-\mathrm{Bi}$ bonds between bismuth oxygen polyhedra, as well as on the ionicity of $\mathrm{Bi}-\mathrm{O}$ bonds which was expressed by Duffy's optical basicity concept.

\section{References}

1) I.-I. Oprea, H. Hesse and K. Betzler, Opt. Mater., 26, 235-237 (2004).

2) K. H. Mahmoud, Int. J. Appl. Ceram. Tec., 6, 279-285 (2009).

3) S. Bale, S. Rahman, A. M. Awasthi and V. Sathe, J. Alloy. Compd., 460, 699-703 (2008).

4) T. Hashimoto, Y. Shimoda, H. Nasu and A. Ishihara, J. Am. Ceram. Soc., 94, 2061-2066 (2011).

5) X. Zhao, X. Wang, H. Lin and Z. Wang, Physica B, 390, 293-300 (2007).

6) B. V. R. Chowdari and Z. Rong, Solid State Ionics, 90, 151-160 (1996).

7) Y. B. Saddeek and M. S. Gaafar, Mater. Chem. Phys., 115, 280-286 (2009).

8) P. S. Rao, Ch. Rajyasree, A. R. Babu, P. M. V. Teja and D. K. Rao, J. Non-Cryst. Solids, 357, 3585-3591 (2011).

9) Y.-H. Na, N.-J. Kim, S.-H. Im, J.-M. Cha and B.-K. Ryu, J. Ceram. Soc. Jpn., 117, 1273-1276 (2009).

10) N. Kitamura, K. Fukumi, J. Nakamura, T. Hidaka, H. Hashima, Y. Mayumi and J. Nishii, Mater. Sci. Eng. B, 161, 91-95 (2009).

11) S. Rani, S. Sanghi, A. Agarwal and N. Ahlawat, J. Alloy. Compd., 477, 504-509 (2009).

12) N. Kitamura, K. Ohno, K. Fukumi, J. Nakamura, T. Hidaka, T. Ikeda, H. Hashima, H. Kozuka and J. Nishii, Jpn. J. Appl. Phys., 49, 082601 (2010).

13) N. Ahlawat, S. Sanghi, A. Agarwal and R. Bala, J. Mol. Struct., 963, 82-86 (2010).

14) H. M. Oo, H. Mohamed-Kamari and W. M. D. WanYusoff, Int. J. Mol. Sci., 13, 4623-4631 (2012).

15) N. Yamashita, T. Suetsugu, T. Einishi, K. Fukumi, N. Kitamura and J. Nishii, Phys. Chem. Glasses: Eur. J. Glass Sci. Technol., Part B, 50, 257-261 (2009).

16) T. Mori, N. Yamashita, H. Kasa, K. Fukumi, K. Kintaka and J. Nishii, J. Ceram. Soc. Jpn., 117, 1134-1137 (2009).

17) N. Kitamura, K. Fukumi, J. Nakamura, T. Hidaka, T.
Ikeda, H. Hashima and J. Nishii, J. Nonlinear Opt. Phys. Mater., 19, 753-759 (2010).

18) S. Khonthon, S. Morimoto, Y. Arai and Y. Ohishi, Opt Mater., 31, 1262-1268 (2009).

19) M. Imaoka and T. Yamazaki, Rep. Inst. Ind. Sci., Univ. Tokyo, 22, 1-40 (1972).

20) S. Kasap, C. Koughia, J. Singh, H. Ruda and S. K. O'Leary, "Springer Handbook of Electronic and Photonic Materials", Ed. by S. Kasap and P. Capper, Springer, New York (2006) Chap. 3, pp. 47-77.

21) A. Paul and R. W. Douglas, Phys. Chem. Glasses, 8, 151-159 (1967).

22) J. A. Duffy and M. D. Ingram, "Optical Properties of Glass" Ed. by D. R. Uhlmann and N. J. Kreidl, Am. Ceram. Soc., Westerville (1991) pp. 159-184.

23) J. E. Huheey, "Inorganic Chemistry, Principles and Structure and Reactivity" 3rd edition, Harper \& Row, Cambridge (1983) Chap. 3, pp. 55-181 (Japanese translated version).

24) K. Fukumi, N. Kitamura, H. Kozuka and S. Kohara, J. Ceram. Soc. Jpn., 126, 992-996 (2018).

25) E. E. Havinga, H. Damsma and M. H. Van Maaren, J. Phys. Chem. Solids, 31, 2653-2662 (1970).

26) S. Schulz, A. Kuczkowski, D. Bläser, C. Wölper, G. Jansen and R. Haack, Organometallics, 32, 5445-5450 (2013).

27) A. Walsh, G. W. Watson, D. J. Payne, R. G. Edgell, J. Guo, P.-A. Glans, T. Learmonth and K. E. Smith, Phys. Rev. B, 73, 235104 (2006).

28) A. F. Williams, "A Theoretical Approach to Inorganic Chemistry”, Springer, Berlin (1979) Chap. 3. pp. 66131.

29) R. T. Sanderson, J. Chem. Educ., 65, 112-118 (1988).

30) R. T. Sanderson, J. Chem. Educ., 65, 227-231 (1988).

31) J. A. Duffy, Phys. Chem. Glasses, 30, 1-4 (1989).

32) J. A. Duffy, J. Non-Cryst. Solids, 297, 275-284 (2002).

33) L. Pauling, Proc. R. Soc. London, Ser. A, 114, 181-211 (1927).

34) S. S. Batsanov, J. Struct. Chem., 8, 335-344 (1967) (translated from Russian).

35) J. Duffy, J. Solid State Chem., 62, 145-157 (1986).

36) J. C. Phillips, Rev. Mod. Phys., 42, 317-356 (1970).

37) B. F. Levine, J. Chem. Phys., 59, 1463-1486 (1973).

38) S. H. Wemple and M. DiDomenico, Jr., Phys. Rev. B, 3, 1338-1351 (1971). 